\section{Endoscopic Management of Complications Related to Esophageal Stenting by Repositioning the Stent without Extraction or Re-Stenting}

Placement of self-expanding metallic stents is a widely accepted technique for palliative treatment of esophagorespiratory fistulas $[1,2]$. Many reports have described technical aspects of extracting migrated stents [3-5]. We describe here a case of stent migration which was managed using a pull-up maneuver, with concomitant balloon dilation of the proximal tip.

A 65-year-old man was treated for a tracheo-esophageal fistula between the right main bronchus and the mid-portion of the esophagus, due to mediastinal lymphadenopathy in acute myeloid leukemia. A covered expandable esophageal stent (Ultraflex, Microvasive/Boston Scientific), $15 \mathrm{~cm}$ in length, was inserted under fluoroscopic control. Sealing of the fistula was complete, as confirmed by barium studies. The patient was readmitted a week later due to recurrent symptoms. Barium studies revealed distal migration

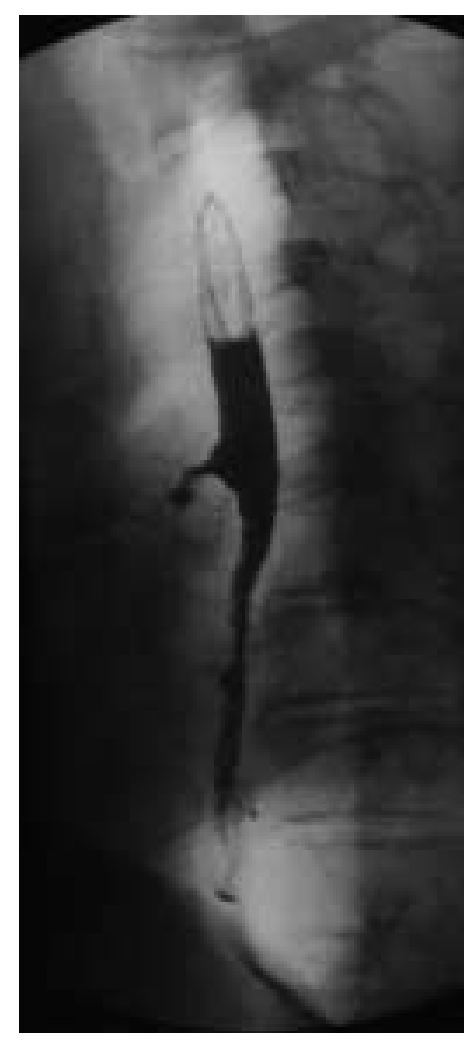

Figure 1 Barium esophagogram showing a tracheo-esophageal fistula. of the stent by about $2 \mathrm{~cm}$ and consequent reopening of the orifice (Figure $\mathbf{1}$ ).

A catheter with a diameter of $3 \mathrm{~mm}$ was introduced via the endoscope's instrumentation channel. The endoscope was removed, leaving the catheter inside the esophageal lumen. A grasper was inserted via the catheter, and the endoscope was reinserted with a second grasper within the instrumentation channel. The first grasper was manipulated with the help of the second (in the endoscope) to hold the proximal margin of the stent. The opposite edge of the stent was then held by the second grasper. The stent was pulled upwards until the proximal margin of the covered part was placed $2 \mathrm{~cm}$ above the fistula opening. To prevent recurrent migration, the stent was fixed to the esophageal mucosa with an endoscopic balloon dilator (18,19,20 CRE Wire-Guided Esophageal Balloon, Boston Scientific/Microvasive).

The success of the intervention was confirmed with a barium study (Figure 2 ). Re-

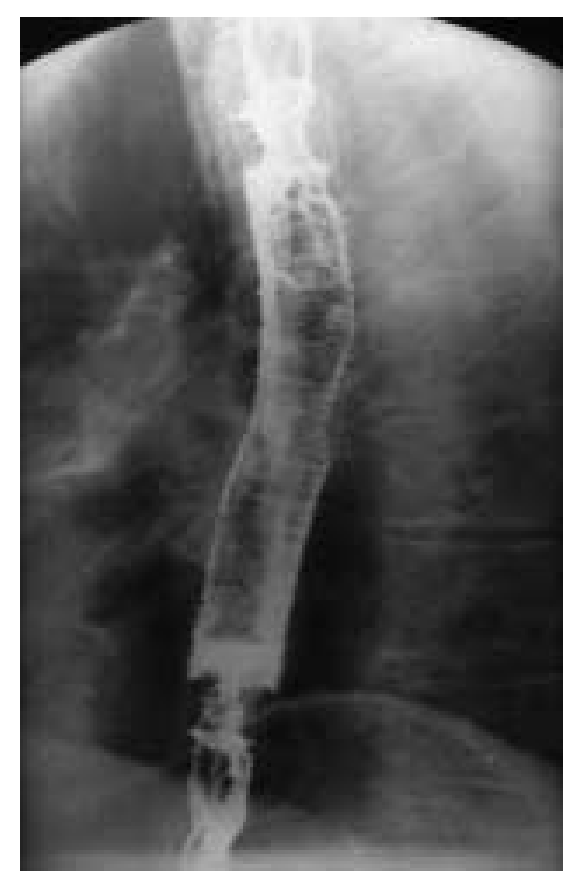

Figure 2 The radiographic view following pulling up and fixation of the stent to the mucosa. peat migration did not occur in the following 3 months before the patient died due to a complication of acute myeloid leukemia.

\section{Tasci' ${ }^{1}$ U. Korman ${ }^{2}$}

${ }^{1}$ Endoscopy Unit, Dept. of General Surgery

${ }^{2}$ Dept. of Radiology, Cerrahpasa School of Medicine, University of Istanbul, Istanbul, Turkey.

\section{References}

${ }^{1}$ Siersema PD, Hop WC, Dees J et al. Coated self-expanding metal stents versus latex prostheses for esophago-gastric cancer, with special reference to prior radiation and chemotherapy: a controlled, prospective study. Gastrointest Endosc 1998; 47: 113 - 120

${ }^{2}$ Shields SJ. Esophageal self-expandable metallic stents. Gastrointest Endosc 1997; 45: 439-442

${ }^{3}$ Rollhauser C, Fleischer DH. Late migration of a self-expandable metallic stent and successful endoscopic management. Gastrointest Endosc 1999; 49: $541-544$

${ }^{4}$ May A, Gossner L, Feess G et al. Extraction of migrated self-expanding esophageal metal stents. Gastrointest Endosc 1999; 49: 524-526

${ }^{5}$ Farkas PS, Farkas JD, Koenigs KP. An easier method to remove migrated esophageal Z-stents. Gastrointest Endosc 1999; 50: $277-279$

\section{Corresponding Author}

\section{Tasci, M.D.}

Cerrahpasa School of Medicine,

Endoscopy Unit, Dept. of General Surgery 34303 Kocamustafapasa

Istanbul

Turkey

Fax: $\quad$ +90-212-6334841

E-mail: ihsantasci@yahoo.com 